\title{
O HOSPITAL INFANTIL COMO MARCO NO ATENDIMENTO AO RECÉM- NASCIDO DE RISCO EM SANTA CATARINA (1987-2009) ${ }^{1}$
}

\author{
Roberta Costa², Maria Itayra Padilha ${ }^{3}$
}

\begin{abstract}
${ }^{1}$ Artigo extraído da tese - Saberes e práticas no cuidado ao recém-nascido em terapia intensiva na década de 1980 em Florianópolis, Universidade Federal de Santa Catarina (UFSC), 2009.

${ }^{2}$ Doutora em Enfermagem. Enfermeira do Hospital Universitário da UFSC. Santa Catarina, Brasil. E-mail: robertanfr@hotmail. com

${ }^{3}$ Doutora em Enfermagem. Professora Associado do Departamento de Enfermagem e da PósGraduação em Enfermagem da UFSC. Pesquisadora do CNPq. Santa Catarina, Brasil. E-mail: padilha@nfr.ufsc.br
\end{abstract}

RESUMO: O objetivo deste estudo é descrever como se deu o processo de implantação da Unidade de Terapia Intensiva neonatal, em Florianópolis, na década de 1980, e apresentar a sua relevância para o cuidado ao recém-nascido de risco. Pesquisa qualitativa, com abordagem sócio-histórica. O contexto do estudo foi o Hospital Infantil Joana de Gusmão. Os sujeitos foram 13 profissionais de saúde que participaram da implantação da unidade. A análise dos dados utilizou o método genealógico. Os resultados indicam que esta unidade representou um marco no cuidado intensivo neonatal catarinense e que os profissionais que contribuíram na implantação e implementação do cuidado foram fundamentais na instituição do saber, das práticas de cuidado ao recém-nascido e na instituição de novos sujeitos profissionais. Conclui-se que a necessidade de atendimento especializado foi a grande propulsora da criação da terapia intensiva neonatal e da constituição do saber profissional para o cuidado ao recém-nascido.

DESCRITORES: Unidades de Terapia Intensiva Neonatal. Recém-nascido. Hospital. História.

\section{CHILDREN'S HOSPITAL AS A REFERENCE FOR AT-RISK NEWBORN CARE IN SANTA CATARINA, BRAZIL (1987-2009)}

\begin{abstract}
The purpose of this study is to describe the implantation process through the 1980's for the neonatal intensive care unit in Florianopolis, Santa Catarina, Brazil, as well as to present its relevance for at-risk newborn care. This is a qualitative research with a socio-historical approach. The context of the study was the Joana de Gusmão Children's Hospital. Those interviewed for this study were 13 health professionals who had a role in implanting the unit. The data was analyzed through theoretical reference. The results indicate that this unit represents a milestone in Santa Catarina neonatal intensive care and the professionals who contributed to the deployment and implementation of care there were fundamental to the institution of newborn care knowledge and practice. We conclude that the need for specialized care was the major propellant for the creation of the neonatal intensive care unit and the construction of professional newborn care knowledge.
\end{abstract}

DESCRIPTORS: Intensive Care Units Neonatal. Newborn. Hospital. History.

\section{EL HOSPITAL INFANTIL COMO UN MARCO DE REFERENCIA PARA LA ATENCIÓN AL RECIÉN NACIDO EN RIESGO EN SANTA CATARINA, BRAZIL (1987-2009)}

\begin{abstract}
RESUMEN: Se trata de una investigación cualitativa, con abordaje socio-histórico, con el objetivo de describir el proceso de implantación de la unidad de cuidados intensivos neonatales en Florianópolis, Santa Catarina, Brzil en la década de 1980, y mostrar la importancia de esta unidad para el cuidado del recién nacido en riesgo. El contexto del estudio fue el Hospital Infantil Joana de Gusmão. Los sujetos de la investigación fueron 13 profesionales de salud que participaron de la implantación de la unidad. Para el análisis de los datos se empleó el método genealógico. Los resultados muestran que esta unidad representó un hito en el cuidado intensivo neonatal catarinense y los profesionales que contribuyeron en la implantación y puesta en práctica de la atención fueron fundamentales en la institución del saber y de las prácticas de cuidado al recién nacido. Se concluye que la necesidad de una atención especializada fue la gran propulsora del cuidado intensivo neonatal
\end{abstract}

DESCRIPTORES: Unidades de Terapia Intensiva Neonatal. Recién nacido. Hospital. Historia. 


\section{INTRODUÇÃO}

Até meados do século XVIII, o hospital funcionou como uma espécie de instrumento de exclusão, assistência e transformação espiritual, na qual a função médico-terapêutica pouco aparecia. Dois movimentos concomitantes e interrelacionados possibilitaram a transformação dos hospitais em instituições médico-terapêuticas: a introdução de mecanismos de disciplinamento (do espaço, das relações e das formas de organização) da instituição que foram demandadas por questões econômicas; o preço atribuído ao indivíduo e à vida humana, bem como a necessidade de evitar epidemias e sua propagação; e a transformação do saber e da prática médicas. ${ }^{1}$ O hospital passou a funcionar não só como uma instituição de disciplinamento, controle e/ou cura de certos tipos de desordens reconhecidas e nomeadas como patológicas, mas, também, como uma instância de acúmulo, registro, produção e veiculação de um tipo específico de saber - a medicina clínica. O hospital transforma-se em lugar de formação privilegiada inicialmente de médicos e, crescentemente, de outros profissionais de saúde, como os da enfermagem. ${ }^{2}$

Diante deste mesmo contexto e da preocupação com a taxa de natalidade e mortalidade infantil, começam a se instituir políticas de atenção a saúde materno-infantil. Dentre elas, a institucionalização do parto, constituiu-se numa tentativa de se controlar o desenvolvimento da população. ${ }^{3}$ Desde então, o entendimento sobre os processos fisio-patológicos referentes à gestante, ao parto e ao recém-nascido avançou pelo desenvolvimento científico e tecnológico, permitindo a intervenção médica para melhoria das condições de saúde materno-infantil.

A preocupação com a assistência ao recémnascido na área da saúde surgiu como um prolongamento da ação da prática obstétrica, a partir do século XX. Inicialmente, as unidades de atendimento ao recém-nascido tinham por finalidade a manutenção e restauração das suas condições de vitalidade, a prevenção de infecções e diminuição da morbi-mortalidade. O objetivo do trabalho nestas unidades era promover a sobrevivência de bebês debilitados em sua adaptação à vida extra-uterina, justificando os investimentos econômicos e sociais para redução da mortalidade infantil e o novo poder-saber médico da neonatologia. ${ }^{4}$

As primeiras instalações de berçários para atender a prematuros surgiram em fins do sé- culo XIX e no início do século XX, passaram a atender os demais recém-nascidos. A finalidade desses berçários era manter a termorregulação dos bebês, alimentá-los através de técnicas cuidadosas e protegê-los de infecções através do isolamento. Ao longo do século XX, os berçários transformaram-se em unidades de internação neonatal e Unidade de Tratamento Intensivo Neonatal (UTIN). ${ }^{5}$

No Brasil, os primeiros berçários surgiram em $1945 .{ }^{6}$ No cuidado ao recém-nascido, a ênfase centrou-se na termorregulação, alimentação, equilíbrio hidroeletrolítico e do sistema cardio-respiratório e prevenção de infecção, restringindo-se a visita dos pais aos berçários. Na segunda metade do século XX, ocorreu uma forte medicalização do nascimento aumentando as intervenções sobre o binômio mãe-filho e, sobretudo na relação entre eles e a família. Os progressos tecnológicos ocorridos após a Segunda Guerra Mundial abriram caminho para o desenvolvimento da indústria médico-hospitalar e para investigações sobre mecanismos fisiopatológicos da gestação, feto e neonato, resultando em avanços na terapêutica e consequentemente na redução da morbi-mortalidade perinatal e neonatal. ${ }^{7}$

Nos últimos trinta anos, grandes mudanças vêm ocorrendo no ambiente das unidades neonatais no Brasil, de certa forma acompanhando a tendência mundial. A incorporação de novas tecnologias, a necessidade de diferentes categorias profissionais, a presença cada vez mais freqüente dos pais e o cuidado de bebês cada vez menores já fazem parte de uma realidade que exige posturas diferentes dos profissionais da equipe de saúde neonatal. ${ }^{8}$

O grande avanço tecnológico e científico a que se assistiu nas últimas décadas tem trazido mudanças para a neonatologia e, essas mudanças se refletem na sobrevivência de bebês cada vez mais imaturos e com pesos de nascimento cada vez menores. Entre estes avanços, está a melhoria nos cuidados básicos ao recém-nascido pré-termo, a introdução da nutrição parenteral, o uso de corticoesteróides antenatal, o conhecimento de novas modalidades ventilatórias e a introdução da terapêutica com surfactante. ${ }^{9-10}$

Neste estudo, a atenção se volta para a UTIN. Esta se constitui em ambiente terapêutico apropriado para tratamento de recém-nascidos de risco, sendo considerada de alta complexidade tecnológica com recursos materiais e equipe multiprofissional especializados. ${ }^{11}$ Em Florianópolis, 
a UTIN do Hospital Infantil Joana de Gusmão (HIJG) foi a primeira unidade com esta denominação e característica na cidade para o atendimento ao recém-nascido. Porém, ao procurar material bibliográfico e documentos, pouco ou quase nada foi encontrado.

Por entender que muitos dos saberes/práticas instituídas no cuidado ao recém-nascido de risco em nosso estado foram influenciados pelo atendimento nesta unidade, decidimos realizar esta pesquisa com o intuito de descrever como se deu o processo de implantação da UTIN em Florianópolis na década de 1980, bem como apresentar a relevância desta unidade para o cuidado ao recém-nascido de risco. Percebendo esta, não como uma forma de reconstruir o passado, mas procurando fazer uma leitura deste passado a partir do discurso dos profissionais que vivenciaram este momento, a fim de contribuir para uma pratica neonatal sensível e individualizada.

\section{METODOLOGIA}

Pesquisa qualitativa, com abordagem sóciohistórica. Neste estudo, adotamos os princípios da Nova história, uma história para o tempo presente, que nos lança a conhecer e compreender uma história-problema, entender que qualquer sociedade proporciona uma história em que passado e presente são iluminados pela discussão e análise de forças permanentes que atuam sobre as vontades humanas. ${ }^{12}$ Assim, possibilita que se saiba quais as forças que estavam em cena em dado momento, como estava pós-acontecimento, se isso contribuiu para seu fortalecimento, enfraquecimento, ou se isso não proporcionou mudança. ${ }^{13}$

Optamos por realizar esta investigação no HIJG, em Florianópolis-SC, por ser este o Hospital de referência para o atendimento de crianças e recém-nascidos de risco do estado de Santa Catarina e local onde foi implantada a primeira UTIN de Florianópolis, em 1987. Os sujeitos da pesquisa foram três médicos, cinco enfermeiras e cinco técnicos/auxiliares de enfermagem que trabalhavam na unidade de terapia intensiva (UTI) geral e/ou UTIN na década de 1980. O número de participantes foi definido a partir da saturação dos dados. Para garantir a anonimato, os sujeitos do estudo foram identificados com letras referentes às categorias profissionais e números (por exemplo, médico M1, enfermeiro E3, técnico de enfermagem TE2 e auxiliar de enfermagem AE1).
Para coleta de dados utilizamos um roteiro de entrevista semi-estruturado, contendo questões relativas a: processo de implantação da UTIN e as práticas de cuidado no período do estudo. Utilizamos a História Oral como método pois esta privilegia a realização de entrevistas com pessoas que testemunharam acontecimentos num determinado contexto social. As entrevistas implicam na percepção do passado como algo que tem continuidade hoje, dentro de um processo histórico em andamento, cujo informante contribuirá com sua percepção dos fatos. ${ }^{14}$ Além disso, utilizamos algumas fontes documentais, tais como livro de ocorrências, atas de reunião e recortes de jornais. Este material foi coletado nos arquivos do HIJG, no Arquivo e na Biblioteca Pública do Estado de Santa Catarina, na Biblioteca da UFSC e no arquivo do jornal Diário Catarinense. O período de coleta de dados foi de outubro de 2008 a março de 2009.

Para análise dos dados foi utilizado o método genealógico foucautiano. Entendendo a genealogia como o estudo das formas de poder: “(...) na sua multiplicidade, nas suas diferenças, na sua especificidade: estudá-las, portanto, como relações de força que se entrecruzam, que remetem umas às outras, convergem ou, ao contrário se opõem $(. . .)^{\prime \prime} .{ }^{15: 71}$ Desta forma, procuramos explorar ao máximo o discurso dos atores que participaram deste estudo, na medida em que as palavras são também construções; na medida em que a linguagem também é constitutiva de práticas/da realidade e produziria como o poder, inúmeros saberes. Após a transcrição e validação de cada entrevista, o material foi organizado em uma tabela contendo duas colunas, na primeira eram colocados os dados brutos e, na segunda buscava-se extrair os enunciados diretamente da simples leitura, tentando conferir-lhes de imediato uma sistematização provisória. Após compilação de todas as entrevistas, procuramos agrupar os enunciados em formações discursivas provisórias.

Construir um panorama geral ajudou-nos a orientar a re-leitura das entrevistas, e possíveis alterações nos modos de reagrupar os enunciados, uma vez que nossas re-leituras conduziram a reconfigurações do que seria analisado inicialmente. Nesse percurso, procuramos realizar agrupamentos temáticos, dando-lhes significados a partir do referencial foucaultiano. Operamos com as entrevistas uma conexão entre discursos que se articulam, que se sobrepõem, que se somam ou, 
ainda, que diferem. Isso significa escapar da fácil interpretação daquilo que está " por trás" dos escritos, procurando explorar ao máximo os materiais. Por um lado, as entrevistas não permitiram "dizer uma ou $a$ verdade sobre as coisas e os fatos, mas pode-se considerá-las como a instância central que, somada a outras," trouxe "informações fundamentais acerca do vivido e" possibilitou uma interpretação (mesmo que provisória e parcial) da história das transformações das práticas e dos saberes no cuidado ao recém-nascido em terapia intensiva. Emergiram assim, cinco agrupamentos temáticos: A necessidade de um atendimento especializado; A mãe de todos; A UTI buscava todo mundo; $\mathrm{O}$ nosso maior problema era a área física; Tinha " $\mathrm{n}$ " brigas.

O projeto de pesquisa foi avaliado e aprovado pelo Comitê de Ética em Pesquisa com Seres Humanos da UFSC sob protocolo $n^{\circ} 242 / 08$ FR 217903 e pelo Comitê de Ética do HIJG sob parecer $\mathrm{n}^{\circ} 086 / 2008$. Os participantes assinaram o Termo de Consentimento Livre e Esclarecido, conforme rege a Resolução 196/96 do Conselho Nacional de Saúde. ${ }^{16}$

\section{RESULTADOS E DISCUSSÃO}

Para descrever como se deu o processo de implantação da UTIN procuramos conhecer como era prestado o atendimento ao recém-nascido antes da abertura desta unidade e quem foram as pessoas que formaram a equipe de saúde da UTIN. O recém-nascido era atendido no berçário ou na UTI pediátrica geral, pelos profissionais que ali atuavam. A inauguração da UTIN começa a aparecer como meta dos gestores do HIJG em meados de 1984, porém este foi um processo bastante moroso envolvendo a disponibilização de uma área física adequada e organização de uma equipe de saúde. A partir da inauguração da UTIN, em 1987, os recém-nascidos passaram a ser cuidados por uma equipe de saúde específica, formada por médicos, enfermeiros e técnicos/auxiliares de enfermagem. Para compor a equipe de enfermagem foram remanejadas duas enfermeiras que atuavam em outras unidades do hospital. Sendo que no período noturno e nos finais de semana não havia enfermeira na unidade, mas sim uma enfermeira geral que realizava supervisão indireta das UTI e do centro cirúrgico. Com relação aos técnicos e auxiliares foram convidados os profissionais que trabalhavam no berçário e na UTI geral que tinham afinidade, experiência e habilidade no cuidado ao recém- nascido. Também, foram contratados funcionários novos que integraram o quadro de funcionários da enfermagem. Com relação à equipe médica, muitos eram residentes de pediatria do Hospital Infantil e a maioria realizou curso de especialização em São Paulo, no Hospital Maternidade Vila Nova da Cachoeirinha. A partir do discurso destes profissionais sobre a UTIN, encontramos cinco agrupamentos temáticos que descrevem este processo e que apresentaremos a relevância desta unidade para o atendimento ao recém-nascido de risco no estado de Santa Catarina.

\section{A necessidade de um atendimento especia- lizado}

A UTIN configura-se como um locus de produção de saber, constituindo-se em ambiente terapêutico apropriado para tratamento de recém-nascidos de risco, sendo considerada de alta complexidade. A introdução destas unidades possibilitou aos recém-nascidos um local específico com profissionais capacitados para atender suas demandas de cuidado.

Ao questionar sobre os motivos para abertura da UTIN, muitos profissionais referem que a unidade era uma necessidade e que havia um aumento da demanda de recém-nascidos de risco. Outros relatam ainda que, a UTIN era um sonho.

Os fatores motivadores da criação desta unidade foram melhorar a assistência, e pelo fato de ser um hospital de referência para diversas especialidades (M1).

O que motivou foi à necessidade mesmo, de prestar um atendimento mais especializado para esse paciente e eu acho que também a possibilidade de profissionais, alguns residentes até nossos lá que saíram para se especializar em neonatologia, que estavam retornando (E3).

A UTI do Hospital Infantil era geral, era UTI para lactente, principalmente. E de vez em quando era admitido recém-nascido, sempre com uma necessidade crescente desta demanda. A abertura da UTIN mudou radicalmente a assistência dos bebês. A partir de lá, em minha opinião, Santa Catarina deu uma virada: redução do indice de mortalidade infantil e mortalidade perinatal, das doenças (M3).

[...] foi uma luta para conseguir a implantação desta primeira UTIN, mas foi um grande avanço, porque os recém nascidos passaram a ser atendidos em área específica (M2).

Era um sonho, a UTIN, os recém-nascidos não deviam ficar na UTI geral (TE2). 
Na realidade o que motivou a abertura é que não existia um centro de neonatologia na grande Florianópolis. A gente recebia os pacientes e não tinha neonatologista suficiente, não tinha material adequado, não tinha uma forma de cuidar de recémnascido (E1).

O discurso dos profissionais revela a necessidade e importância de uma unidade específica para o atendimento do recém-nascido de risco. Com a implantação da UTIN, aos poucos foi se constituindo um saber/fazer específico com relação às práticas no cuidado ao recém-nascido de risco. Assim, as práticas de cuidado na UTI possibilitaram a operação de um saber científico sobre o corpo do recém-nascido. A UTIN, enquanto espaço específico de atendimento do recém-nascido de risco configura-se como um campo de conhecimentos e práticas, sendo que este saber e fazer consolidam-se a partir das vivências/experiências do cotidiano do trabalho dos profissionais de saúde.

Desta forma, podemos re-afirmar a necessidade e importância de se instituir um local específico para este atendimento, capacitando adequadamente os profissionais, permitindo a organização das práticas de cuidado, e disponibilizando equipamentos tecnológicos que possibilitem a promoção da qualidade da assistência e o aumento da sobrevivência neonatal.

\section{A mãe de todos}

A UTIN do HIJG representou um marco no atendimento ao recém-nascido de risco, esta se consolidou como centro de referência em Santa Catarina, atendendo à quase totalidade dos recém-nascidos de alto risco nascidos no estado. Desde a sua inauguração, esta unidade recebeu bebês provenientes das diversas maternidades de Florianópolis, assim como de outros hospitais de todo estado.

O HIJG atua como pólo de referência Estadual para o atendimento das crianças com patologias de baixa, média e alta complexidade. ${ }^{17}$ Desta forma, a UTIN deste hospital era referência no atendimento especializado ao recém-nascido, sendo então considerada "a mãe de todos", pois recebia recém-nascidos de todo Estado. Ademais neste Hospital concentram-se diversas especialidades médicas, tais como: cirurgia pediátrica, cardiologia, pneumologia, nefrologia, geneticista, entre outras, que desempenham papel importante nesta referência.
Ao questionar os profissionais de saúde sobre a demanda de recém-nascidos internados na UTIN, os mesmo relatam que a unidade estava sempre lotada, sendo que as crianças vinham de diversas regiões do Estado, como podemos ver nos depoimentos a seguir:

A UTI do Hospital Infantil Joana de Gusmão era referência. É como se a implantação do cuidado intensivo neonatal em Santa Catarina, em 87, fosse um marco tanto no saber, como nos cuidados, como nos resultados. Constituiu um divisor de resultados (M3).

Por que não tinha UTI neo no interior do Estado quase. Então vinha tudo pra cá. [...] Então vinha muita criança, muita criança do sul (TE2).

A UTI tava sempre lotada. Sempre lotada, cirurgias cardíacas. [...] porque não tinha outra. [...] A referência era Florianópolis (TE4).

Apesar do surgimento de novas UTIN nas maternidades de Florianópolis e de todo o Estado, o nivel de atividade da UTIN do HIJG tem sido intensa, nesses 22 anos de existência. No período de 16/03/1987 a 30/04/2009 foram registradas 4.398 internações (M1).

Tudo drenava para cá, era a gente que fazia o transporte das crianças. A gente ia buscar crianças nas maternidades. Na Maternidade A, na B, no Hospital $\mathrm{Xl}(\mathrm{E} 2)$.

Quando precisava chegava a botar sete leitos (AE1).

Cabe salientar que neste momento histórico, na Constituição Federal de 1988, era aprovado o Sistema Único de Saúde, que preconizava a organização dos serviços de saúde de modo regionalizado e hierarquizado. ${ }^{18}$ Este sistema de saúde traz a tona a questão do sistema de referência e contra-referência, como forma de organização do atendimento de menor complexidade para o de maior complexidade. O sistema de referência compreende o trânsito do nível menor para o de maior complexidade. ${ }^{19}$ A referência representa o maior grau de complexidade, para onde o usuário é encaminhado para um atendimento com níveis de especialização mais complexos, os hospitais e as clínicas especializadas. ${ }^{20} \mathrm{O}$ encaminhamento deve ser desencadeado quando for constatada a insuficiência de capacidade resolutiva do órgão encaminhador e deve obedecer a normas e procedimentos estabelecidos.

Com relação ao cuidado neonatal, percebemos que a UTIN do HIJG sempre foi uma unidade especializada para o atendimento do recém-nascido. Nos primórdios desta unidade, os 
neonatos com qualquer alteração fisiopatológica, prematuros e/ou de baixo peso eram encaminhados a esta unidade. É importante salientar que os serviços especializados, como cirurgia pediátrica, neurologia, cardiologia concentravam-se no HIJG. Com o passar do tempo, foi instituído um saber/ fazer que direcionou as práticas de cuidado a este segmento populacional e possibilitou a abertura de outras unidades em diferentes regiões do estado. Como consequência deste processo os recém-nascidos de menor complexidade passaram a ser atendidos nas próprias maternidades - em berçários de alto risco ou em outras UTIN criadas posteriormente, buscando a descentralização deste atendimento. Também, novos profissionais foram adquirindo conhecimento e habilidade no cuidado ao recém-nascido.

\section{A UTI buscava todo mundo}

O transporte intra-hospitalar neonatal pode se constituir em risco adicional para o neonato criticamente doente e, por isso, deve ser considerado como uma extensão dos cuidados realizados na UTI. Vale lembrar que para o transporte intra-hospitalar e inter-hopitalar são necessários equipamentos e pessoal habilitado. ${ }^{21} \mathrm{O}$ transporte neonatal está intimamente ligado a história da UTIN do HIJG. Por ser esta a unidade de referência estadual, muitas vezes os profissionais de saúde do HIJG que realizavam o transporte de recém-nascidos de outras unidades/maternidades para o HIJG. Muitos relatam que como as outras Instituições não tinham profissionais habilitados pra este tipo de transporte, eram os próprios profissionais do HIJG que acabavam realizando a transferência destes bebês. Muitos profissionais descrevem esta prática como arriscada e inadequada.

No início nós íamos buscar na Maternidade A e na Maternidade B, quando era cirúrgico. Na Maternidade A mesmo os prematuros a gente ia buscar. Naquela época a gente fazia muito transporte louco. [...] a gente saia daqui com paciente gravíssimo (TE2).

A gente que tinha que ir buscar. É super complicado. Porque a partir do momento que tu pegas o paciente, a responsabilidade passa a ser tua. E às vezes a gente pegava o paciente completamente descompensado por um tratamento inadequado e se ele viesse a ter alguma complicação no trajeto ou logo que chegasse a culpa já era nossa teoricamente (E1).

Nós íamos buscar. Eles ligavam dizendo, oh tem um paciente assim e assim. A gente arrumava a incu- badora de transporte, outra que nós tínhamos aí. E a gente ia buscar na Maternidade A, na Maternidade B e no Hospital X depois quando abriu (TE1).

De acordo com os relatos dos profissionais de saúde percebemos que o transporte neonatal inter-hospitalar foi uma prática instituída a partir da abertura da UTI neonatal. Que a criação desta unidade representou um avanço no atendimento ao recém-nascido, possibilitando que os mesmos tivessem uma unidade específica, com profissionais capacitados e equipamentos adequados para garantir a sua sobrevida. Entretanto, verificamos que este transporte não corria de modo adequado, pois a mesma equipe que atuava na UTIN acabava se responsabilizando por este transporte, o que prejudicava a assistência nos dois segmentos, tanto na unidade que acabava ficando com um número menor de profissionais quanto no transporte, pois nem sempre o médico estava presente.

No Brasil, existem alguns estudos que sinalizam as intercorrências clínicas apresentadas por recém-nascidos durante o transporte entre diferentes instituições. O primeiro foi realizado em Florianópolis com 122 transportes neonatais para a UTI do Hospital Infantil Joana de Gusmão em 1992/1993. O segundo, efetuado em Porto Alegre, com 55 recém-nascidos transferidos para a UTI do Hospital Materno-Infantil Presidente Vargas de fevereiro a novembro de 2000. O terceiro, em Recife, com 234 neonatos transferidos para o Berçário do Instituto Materno Infantil de Pernambuco em 2001. ${ }^{21}$

Especificamente, no estudo realizado em Florianópolis, ${ }^{22}$ na UTIN do HIJG, foram identificadas algumas falhas neste transporte, tais como, falta de profissionais capacitados para esta prática, falta de equipamentos, longas distâncias percorridas em ambulâncias, o que acarretou em complicações nos recém-nascidos como, por exemplo, hipoglicemia, hipotermia, distúrbios respiratórios, piora do estado geral. $\mathrm{O}$ resultado deste estudo mostra que, a organização do transporte neonatal é fundamental, tanto na escolha da equipe de saúde como do veículo de transporte adequado e bem equipado, para que possa ser instituída uma assistência de qualidade com melhora dos resultados perinatais. O transporte neonatal, assim como as demais práticas de cuidado ao recém-nascido de risco, envolve uma trama de relações de poder/saber que foi sendo instituída ao longo do tempo a partir da experiência dos profissionais de saúde 
possibilitando a consolidação de um corpo de conhecimento específico.

\section{O nosso maior problema era a área física}

A área física foi apontada por todos os profissionais como o grande problema da UTIN. Quando foi inaugurada a estrutura física foi instalada em uma área provisória em um espaço cedido pelo centro cirúrgico. Entretanto, os profissionais de saúde desenvolveram práticas de cuidado nesta unidade até dezembro de 2008, quando foi inaugurada a nova UTIN do HIJG. Portanto, foram mais de 20 anos atuando em um espaço provisório.

Na época, a dificuldade era a área física. Porque a recuperação não liberava o espaço [...]. Então era uma luta para conseguir que a recuperação dividisse o espaço, porque eles não aceitavam assim. A chefia do centro cirúrgico não liberava o espaço para construir a UTI neo [...], foi muito difícil abrir espaço. A gente foi fazendo umas adaptações que não era o ideal. $O$ ambiente era muito agradável. Eu gostava, apesar de ser improvisado (TE2).

Foi feito um plano, com área física pequena, mas que, seria uma acomodação transitória [...]. Mas, em termos de humanização a área física era acanhada (M2).

Então ia fazer uma UTI neonatal provisória, que ficou definitiva até hoje (TE3).

A área física não mudou nada. Não teve modificação ao longo dos anos (E1).

O que eu lembro é que eu discutia muito era a questão da área física. Eu lembro porque tinha muita discussão ali atrás quando a gente ia é definir em relação à área física foi uma briga feia assim a área física, atéque chegamos a um consenso, mas foi bem dificil (E3).

O ambiente físico? Era um aperto e o que é pior, ele está exatamente igual a quando foi inaugurada. Com agravante que deve estar mais deteriorado. Mas está exatamente igual e desde que abriu ela tem uma proposta de ampliação, de mudança. Então assim, o espaço era mínimo, às vezes quase encostada uma incubadora na outra, os respiradores chegavam a enroscar os pés, com toda parafernália que tem para uma UTI aquilo era impossível (E1).

Percebemos com estes depoimentos, como foi difícil conseguir uma área física adequada destinada a UTIN, apesar de saber a necessidade e importância deste local. Nesta categoria há destaque para a questão da disputa do espaço, bem como do controle deste espaço. A disputa por espaço dentro do hospital é uma constante em muitas Instituições, sendo que este poder de decisão quase sempre é exercido pelo profissional médico.

Uma área física adequada é imprescindível para o bom funcionamento da UTIN, sendo que a Agência Nacional de Vigilância Sanitária (ANVISA) descreve que, toda UTI deve obedecer aos requisitos quanto à estrutura física, além de estar em conformidade com os critérios de circulações internas e externas, de instalações prediais ordinárias e especiais (hidro-sanitárias; elétricas e eletrônicas; fluído-mecânicas; de oxigênio e ar comprimido), de condições ambientais de conforto, de condições de controle de infecções e de condições de segurança contra incêndio, determinados na legislação. ${ }^{23}$ Mesmo com esta regulamentação, o discurso dos profissionais de saúde revela que a área física destinada a UTIN foi um grande desafio, uma vez que este local teve que ser negociada com outros setores do hospital. O local onde foi implantada a UTIN configurouse com um espaço provisório e pequeno, sendo considerado inadequado por alguns profissionais. Ao visualizarmos esta área, temos um salão onde eram dispostos quatro berços/incubadoras, um isolamento e uma bancada para prescrição médi$\mathrm{ca}$, onde os profissionais podem controlar todo o espaço e os recém-nascidos/famílias que estavam internados ali. Este mecanismo possibilita o exercício do poder dos profissionais sobre o espaço e sobre o neonato. ${ }^{1}$

\section{Tinha "n" brigas}

Apesar dos avanços nas práticas de cuidado ao recém-nascido os profissionais descrevem que houve algumas brigas, ou seja, disputa de poder, entre os diferentes personagens desta história. No cotidiano do cuidado emergiram brigas entre enfermeiro e técnicos/auxiliares de enfermagem, enfermagem e médicos, médicos e as diferentes especialidades médicas, caracterizando o cenário da UTIN, como um espaço de negociações e dominação. Acreditamos, entretanto, que este poder possibilitou a constituição do saber e das práticas de cuidado intensivo neonatal.

Essas dificuldades, eu acho que elas são humanas, mas elas existem ainda. Ou seja, no meio médico, no meio da saúde, no meio da enfermagem existem essas questões pessoais, de orgulho, de coisas ressentidas, de sentimentos que às vezes, assim, não são legais, mas acabam existindo e dificultando muita coisa. Tem uma competitividade, um ciúme, coisas do 
tipo. Isso existe. Infelizmente, eu acho que continuará existindo por um tempo (M3).

Havia, claro, uns momentos de indisposição, mas no geral, era uma relação boa (E3).

Na época as crianças não recebiam estes sedativos como hoje em dia. Era criança extubada todo dia, no banho [...] toda manhã era uma brigaçada (TE1).

A gente vê alguns atritos, mas depois que passa algum tempo, tu vê que aquela resistência até cria respeito $(\mathrm{E} 4)$.

Estes conflitos configuram-se relações de poder, que possibilitam o aprimoramento do conhecimento científico e o desenvolvimento de novas práticas de cuidado ao recém-nascido. Entendendo poder aqui como um fenômeno relacional, como algo "que circula, ou melhor, como algo que só funciona em cadeia. Funciona e se exerce em rede. Nas suas malhas os indivíduos não só circulam, mas estão sempre em posição de exercer este poder e de sofrer sua ação; nunca são o alvo inerte ou consentido do poder, são sempre centros de transmissão" . 1:183

Os discursos dos profissionais também revelaram, muitas vezes, a questão do poder autoritário - o poder de tomar decisões que orientam as ações dos outros.

Era o que eles queriam. Tinha que ser como eles, os médicos, determinavam. O médico mandava e a enfermagem obedecia. Para mim eu achava o fim da picada essa relação. Eu nunca aceitei, porque eu sempre fui muito rebelde. (TE4).

Como hoje em dia a gente conversa bastante, a gente aproxima mais o médico ao enfermeiro, dos funcionários. Antigamente não era assim. O médico passava, nem tinha. Então os funcionários se achavam super, e eles tinham a politica deles e eles meio que mandavam [...]. Então foi um processo que você vai explicando, você vai dizendo, mudando hábito. Então foi tudo, as coisas não foram assim de uma hora para outra (M1).

Eu já sou aquela que compra briga, mas eu sou mais tranqüila. Eu mostrava o meu ponto de vista, quer aceitar tudo bem, não quer. Eu posso até não mudar o meu ponto de vista, mas sou mais maleável. Como diz o outro, eu fico comendo pelas bordas (E5).

O hospital, assim como as demais instituições, está permeado pelos processos de dominação, em que o poder vai se produzindo, transformando-se, configurando relações, estando, portanto, presente no processo de trabalho. ${ }^{24}$

No discurso dos profissionais de saúde observamos conflitos entre as diferentes especiali- dades médicas, entre os médicos e a enfermagem, entre enfermeira e técnico/auxiliares de saúde, mas também há falas que referem que o técnico/ auxiliar de enfermagem exercia poder sobre o médico. Mais uma vez se revela o poder/saber - e os processos de dominação - desta vez com uma vinculação ao poder decisório. Em toda relação de poder ocorrem resistências, como atitudes e posicionamentos que são variáveis, que induzem a estados de poder e produzem novos efeitos, avançando sobre os domínios que até o momento não eram concebidos. ${ }^{1}$

O poder produz saber, e não simplesmente favorecendo-o porquê o serve ou aplicando-o porquê é útil. Poder e saber estão diretamente implicados; não há relação de poder sem constituição correlata de um campo de saber, nem saber que não suponha e não constitua ao mesmo tempo relações de poder. ${ }^{25}$

\section{CONSIDERAÇÕES FINAIS}

Ao descrever o processo de implantação da UTIN no HIJG percebemos que a necessidade de um atendimento especializado foi a grande propulsora para a criação e abertura desta unidade. A demanda cada vez maior de recém-nascidos de risco e o alto índice de mortalidade neonatal foram fatores que desencadearam o processo de implantação desta unidade. Além disso, tivemos um grupo de profissionais que não olvidou esforços para destinar uma área física e formar a equipe de profissionais desta unidade. A implantação de uma UTIN em um hospital de referência estadual no cuidado à criança transformou esta num centro de referência especializado no cuidado ao recém-nascido de risco, fazendo com que esta unidade ficasse caracterizada como "a mãe de todos". As maternidades da grande Florianópolis assim como diversas instituições do estado passaram a encaminhar os recém-nascidos que necessitavam de algum tipo de atendimento especializado para esta unidade.

Diante deste contexto, os profissionais que atuaram nesta UTIN desenvolveram durante muito tempo o transporte dos recém-nascidos, principalmente das maternidades da grande Florianópolis. Esta prática de cuidado continua viva na memória dos profissionais visto que era uma prática arriscada e, muitas vezes, inadequada, mas que possibilitou a sobrevivência de muitos recém-nascidos e a mudança no panorama do atendimento neonatal. 
Outro grande marco na história desta unidade foi a disponibilização da área física, ou seja, de um espaço adequado ao atendimento neonatal. Muitos profissionais referem este como o maior problema na época da implantação da unidade e que perdurou ao longo do tempo por mais de 20 anos. Por ser um espaço improvisado e provisório, muitos profissionais tinham a esperança que um dia teriam uma área específica e adequada a UTIN. Um sonho que se concretizou recentemente, quando em dezembro de 2008 foi inaugurada a nova área da UTIN do HIJG.

Com a implantação da UTIN, tivemos a introdução de mecanismos de disciplinamento (do espaço, das relações e das formas de organização) e a transformação do saber e da prática no cuidado ao recém-nascido. É importante apontar que esta unidade representou um marco no cuidado intensivo neonatal catarinense. Os profissionais que contribuíram na implantação e implementação do cuidado nesta unidade foram fundamentais na instituição do saber, das práticas de cuidado ao recém-nascido de risco e na instituição de novos sujeitos profissionais. Este processo vem resultando na redução da morbidade e mortalidade neonatal e na aquisição de conhecimento científico relacionado ao recémnascido de risco.

\section{REFERÊNCIAS}

1. Foucault M. Microfísica do Poder. $3^{\mathrm{a}}$ ed. Rio de Janeiro (RJ): Graal; 1982.

2. Meyer DEE. Processos coletivos de produção de conhecimento em saúde: um olhar sobre o exercício de enfermagem no hospital. Rev Bras Enferm. 2006 Fev; 59(1):95-9.

3. Nagahama EEI, Silvia MS. A institucionalização médica do parto no Brasil. Ciênc Saúde Coletiva. 2005 Jul-Set; 10(3):651-7.

4. Scochi CGS. A humanização da assistência hospitalar no bebê prematuro: bases teóricas para o cuidado de enfermagem [livre docência]. Ribeirão Preto (SP): Universidade de São Paulo, Escola de Enfermagem de Ribeirão Preto; 2000.

5. Kamada I, Rocha SMM. As expectativas de pais e profissionais de enfermagem em relação ao trabalho da enfermeira em UTIN Rev Esc Enferm USP. 2006 Set; 40(3):404-11.

6. Loyola MA. A cultura da puericultura. Novos Estudos Cebrap, 1983 Mar; 2(1):40-6.

7. Scochi CGS; Costa IAR; Yamanaka NM. Evolução histórica da assistência ao recém-nascido: um panorama geral. Acta Paul Enferm. 1996; 9(Esp):96-101.
8. Lamy ZC. Unidade neonatal: um espaço de conflitos e negociações [tese]. Rio de Janeiro (RJ): Fundação Oswaldo Cruz- Instituto Fernandes Figueira; 2000.

9. Leone CR. Epidemiologia, desafios e perspectivas. In: Marba ST, Costa HPF. O recém-nascido de muito baixo peso. São Paulo (SP): Atheneu; 2004.

10. Santos MCL, Moraes GA, Vasconcelos MGL, Araújo EC. Sentimentos de pais diante do nascimento do recém-nascido prematuro. Rev Enferm UFPE On Line. 2007 Abr; 1(2):111-20.

11. Kamada I; Rocha SMM; Barbeira CBS. Internações em Unidade de Terapia Intensiva Neonatal no Brasil: 1998-2001. Rev Latino-am Enfermagem. 2003 JulAgo; 11(4):436-43.

12. Padilha MICS, Borenstein MS. O método de pesquisa histórica na enfermagem. Texto Contexto Enferm. 2005 Out-Dez; 14(4):575-84.

13. Le Goff J, organizador. A história Nova, Trad. Eduardo Brandão. $4^{\mathrm{a}}$ ed. São Paulo (SP): Martins Fontes; 1998. (O homem e a história) p.4.

14. Meihy JCSB. Manual de história oral. $2^{\mathrm{a}}$ ed. São Paulo (SP): Edições Loyola; 2002.

15. Foucault M. Resumo dos cursos do Collège de France (1970 - 1982). Rio de Janeiro (RJ): Jorge Zahar; 1997.

16. Ministério da Saúde (BR), Conselho Nacional de Saúde, Comitê Nacional de Ética em Pesquisa em Seres Humanos. Resolução 196, de 10 de outubro de 1996: Diretrizes e normas regulamentadoras de pesquisa envolvendo seres humanos. Brasília (DF); 1997.

17. Santa Catarina. Secretaria do Estado de Santa Catarina, Hospital Infantil Joana de Gusmão [online]. [acesso 2009 Jun 10] Disponível em: http:/ / www.saude.sc.gov.br/HIJG/instituicao.htm

18. Ministério da Saúde (BR), Secretaria Executiva. Sistema Único de Saúde: princípios e conquistas. Brasília (DF): MS; 2000.

19. Witt RR. Sistema de referência e contra-referência num serviço de saúde comunitária. Rev Gaúcha Enferm. 1992 Mar; 13(1):19-23.

20. Fratini JRG, Saupe R, Massaroli A. Referência e contra-referencia: contribuição na integralidade em saúde. Cienc Cuid Saude. 2008 Jan-Mar; 7(1):65-72.

21. Vieira ALP, Guinsburg R, Santos AMN, Peres CA, Lora MI, Miyoshi MH. Transporte intra-hospitalar de pacientes internados em UTI Neonatal: fatores de risco para intercorrências Rev Paul Pediatr. 2007 Set; 25(3):240-6.

22. Silva CV, Pereira LD. Transporte neonatal em Santa Catarina. Arq Catarin Med 1995; 24: 6-11.

23. Brasil. Agência Nacional de Vigilância Sanitária. Portaria $n^{\circ}$ 466/MS/SVS de 04 de junho de 1998. Estabelece o Regulamento Técnico para o Funcionamento dos Serviços de Tratamento 
Intensivo e sua respectiva classificação de acordo com o grau de complexidade, capacidade de atendimento e grau de risco inerente ao tipo de atendimento prestado. Diário Oficial da União, 05 junho de 1998.
24. Gaíva MAM, Scochi CGS. Processo de trabalho em saúde e enfermagem em UTI neonatal. Rev Latinoam Enfermagem. 2004 Mai-Jun; 12(3):469-76.

25. Foucault M. Vigiar e punir. $4^{\mathrm{a}}$ ed. Petrópolis (RJ): Vozes; 1987. 